\title{
Forward
}

\section{Challenging Views of Alzheimer's disease}

\author{
Keith A. Crutcher ${ }^{\mathrm{a}}$, Stephen R. Robinson ${ }^{\mathrm{b}}$ and Mark A. Smith ${ }^{\mathrm{c}}$ \\ a Department of Neurosurgery, University of Cincinnati Medical Center, Cincinnati, OH, USA \\ ${ }^{\mathrm{b}}$ Department of Psychology, Monash University, Clayton, Victoria, Australia \\ ${ }^{\mathrm{c}}$ Institute of Pathology, Case Western Reserve University, Cleveland, OH, USA
}

Most scholars would agree that once people accept dogma as fact, novel research on non-dogma related items is stifled. Further, the only way to advance science is by testing, not proving, hypotheses. However, such aspects are often forgotten in the race for publications, profits, fame, and notoriety. This is true, none more so, in the field of Alzheimer's disease.

The papers in this volume emerged from a novel experiment. Would investigators be willing to bring their ideas to an open forum, submit them to critical debate, and perhaps leave with a better appreciation of the breadth and depth of ideas driving the field of Alzheimer's disease research? The summaries published here are submitted as evidence that the experiment was, in fact, successful. Some of the ideas that were debated at this conference are still in their infancy, some have become icons. None emerged as clear victors, but all were given a chance to be heard. Perhaps most encouraging of all was that the discussion at each session was both cordial and critical. The meeting exceeded all expectations, offering opportunities to consider perspectives that others have dismissed long ago as being irrelevant. You be the judge. Although the written word is often a poor reflection of dynamic exchanges, such as occurred at this meeting, these summaries do provide at least some of the main issues and hypotheses that emerged. Based on this success, plans are already underway for our second debate conference, scheduled to be held in the summer of 2003 . The goal is to broaden the scope to include debates on diagnostic and therapeutic aspects of Alzheimer's disease. You are invited. Preparations are under way.
Please give us your ideas and suggestions at our web site www.worldeventsforum.com/alzheimer.html.

\section{Acknowledgements}

We gratefully acknowledge the financial support of our supporters and sponsors:

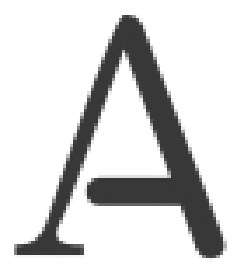

$$
\begin{aligned}
& \overline{A L Z H E I M E R} \\
& \text { RESEARCH } \\
& \text { FO R M M }
\end{aligned}
$$

Alzheimer's Research Forum
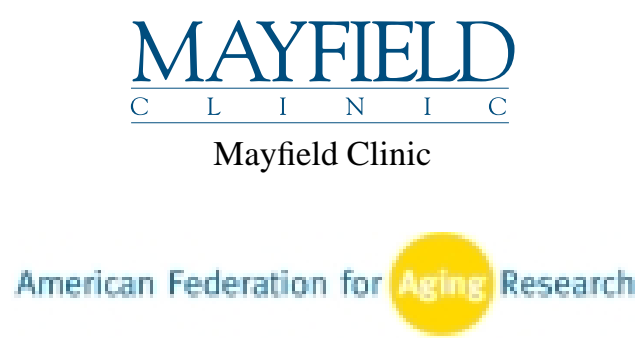

Paul F. Glen Sponsorship Fund in cooperation with the American Federation for Aging Research 


\section{ALZ / EIMER'S}

Alzheimer's Association

Finally, we are indebted to World Events Forum (www.worldeventsforum.com) for their devoted efforts and conference management team, which made this meeting the success that it was.

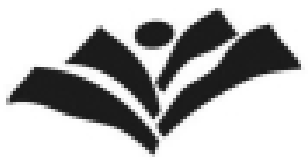

WORLD EVENTS FORUM

Moing the Bese Event? Benner 